\title{
The Usage of the Dental Operating Microscope among Young Dentists in Tîrgu Mureș: A Questionnaire Survey
}

\author{
Andrea-Csinszka Kovács-Ivácson, Mónika Kovács, Monica Monea, Mihai Pop \\ Discipline of Odontology and Oral Pathology, Faculty of Dentistry, University of Medicine and Pharmacy, Tîrgu Mureș, Romania
}

\section{CORRESPONDENCE}

Andrea-Csinszka Kovács-Ivácson

Str. Gheorghe Marinescu nr. 38

540142 Tîrgu Mureș, Romania

Tel: +40 740026885

E-mail: icsinszka@yahoo.com

\section{ARTICLE HISTORY}

Received: October 30, 2017

Accepted: November 4, 2017
Mónika Kovács • Str. Gheorghe Marinescu nr. 38, 540142 Tîrgu Mureș, Romania. Tel: +40 265215551 , E-mail: ti_monikka@yahoo.com

Monica Monea - Str. Gheorghe Marinescu nr. 38 540142 Tîrgu Mureș, Romania. Tel: +40 265215551 E-mail: monea_monica@yahoo.com

Mihai Pop • Str. Gheorghe Marinescu nr. 38, 540142 Tîrgu Mureș, Romania. Tel: +40 265215 551, E-mail: mihaipop_99@yahoo.com

\begin{abstract}
Introduction: In the last 15 years, the most important revolution in dentistry has been the introduction and then the widespread adoption of the dental operating microscope. The aim of this study was to evaluate the usage of the dental operating microscope among young specialized and general practitioner dentists in Tîrgu Mureș. Material and Methods: A 9-point questionnaire about dental microscope usage was distributed among endodontists, practitioners of other specialties, and general practitioners with less than 10 years of experience. Results: According to our results, the dental operating microscope is used mainly during root canal therapy by endodontists. Practitioners of other specialties (prosthetists, alveolar dental surgeons, and orthodontists) use the microscope in a small percentage during coronal restoration, prosthetics, or periodontal surgery. Most general practitioners are not interested in using magnification in their practice. Conclusions: Endodontists use the dental operating microscope when they face complicated cases and have access to it. Working under magnification is awakening the interest of doctors of other specialties also. Private practices should invest in acquiring a microscope, and young general practitioners should be motivated in using it during dental treatments.
\end{abstract}

Keywords: dentistry, dental operating microscope, endodontics

\section{INTRODUCTION}

Not so long ago, endodontics has been considered a blindfolded therapy in dentistry, because doctors performed the root canal therapy without seeing anything, using only tactile sensitivity. The only way to "see" inside the root canal system was to take a radiograph. Most endodontic procedures occurred in a visual void where the doctor's dexterity, mental imaging, and perseverance played a critical role. Before the introduction of the operating microscope, doctors could only "feel" the presence of a problem - a ledge, a perforation, a blockage, or a broken instrument. ${ }^{1}$

After the introduction of magnification in some fields of surgery, experiments started on developing a microscope usable in dentistry as well. In 1978, Dr. Harvey Apotheker, a dentist from Massachusetts and Dr. Géza Jakó, an otolaryngol- 
ogist began the development of a microscope specifically designed for dentistry. ${ }^{2}$ The first dental microscope, the 'DentiScope' (1981) was manufactured by Chayes-Virginia Inc., USA and marketed by the Johnson and Johnson Company. Dr. Gabriele Pecora gave the first presentation on the use of the dental operating microscope (DOM) in surgical endodontics at the 1990 annual session of the American Association of Endodontists in Las Vegas, Nevada. ${ }^{3}$ In the last 15 years, the most important revolution has been the introduction and then the widespread adoption of the dental operating microscope. ${ }^{4}$

The resolution power of the human eye is only $0.2 \mathrm{~mm}$. Clinically, most dental practitioners are not able to see an open margin smaller than $0.2 \mathrm{~mm}$, so during dental interventions in many cases optical aids (loupes, microscopes, surgical headlamps, fiber optic handpiece lights, etc.) can be of assistance. ${ }^{5}$

Not only endodontists, but restorative dentists, prosthetists, periodontists, and maxillofacial surgeons also routinely perform procedures requiring resolution beyond the $0.2 \mathrm{~mm}$ limit of human sight. Crown margins, scaling procedures, incisions, root canal location, caries removal, furcation and perforation repair, post placement or removal, and bone- and soft- tissue grafting procedures are only a few of the procedures where the use of magnification eases the doctor's work. ${ }^{6,7}$

The aim of this study was to evaluate the usage of the operating dental microscope among young specialized and general practitioner dentists in Tîrgu Mureș.

\section{MATERIAL AND METHODS}

A 9-point questionnaire about dental microscope usage was distributed among young dentists working at our dental college and in private practices in Tîrgu Mureş, Romania.

The questionnaires were distributed among doctors personally or via internet (e-mail, Facebook). Doctors were allowed to mark as many possibilities as they wanted, except for the Yes/No questions.

The completed questionnaires were collected and distributed into three groups, as follows:

- Group 1 - endodontists;

- Group 2 -practitioners of other specialties (prosthetists, dental alveolar surgeons, and orthodontists);

- Group 3 - general practitioners with less than 10 years of experience.

Statistics were performed using GraphPad Prism, and Microsoft Excel sheets have been used to generate graph- ics. The statistics were analyzed using the Chi square test to find the significance of the parameters between the groups. The statistical significance was set at a p value of 0.005 .

\section{RESULTS}

In total, 100 questionnaires were distributed among young specialized and general practitioners in Tîrgu Mureş. Overall response rate was $69 \%$. Sixty-nine persons completed the questionnaire: 18 endodontists, 21 practitioners of other specialties, and 30 general practitioners.

Young general doctors with less than 10 years of experience did not use the dental operating microscope in their practice except for one person (3\%) and did not have any information about it either; $65 \%$ from the asked persons did not use magnification because the private practice did not own a dental microscope and were not interested in using it, while $35 \%$ preferred sending patients to specialists, when magnification was needed. The use of a dental operating microscope was considered to be useful during endodontic treatments $(87 \%)$ and in implantology/maxillofacial or periodontal surgical interventions (60\%), followed by odontotherapy and prosthetic treatments in almost the same percentages, 24 and $22 \%$ respectively. Only $15 \%$ of the doctors would lodge in acquiring a microscope for their private practice in the future, this percentage being higher (reaching 40\%) only if they would specialize in endodontics. Also, $45 \%$ of the asked persons were not interested in buying a dental microscope.

Furthermore, $14 \%$ of practitioners of other specialties (prosthetists, dental alveolar surgeons, and orthodontists) stated that they use magnification during dental interventions such as odontotherapy, prosthetics, or surgical interventions. In case of a complicated root canal therapy, all

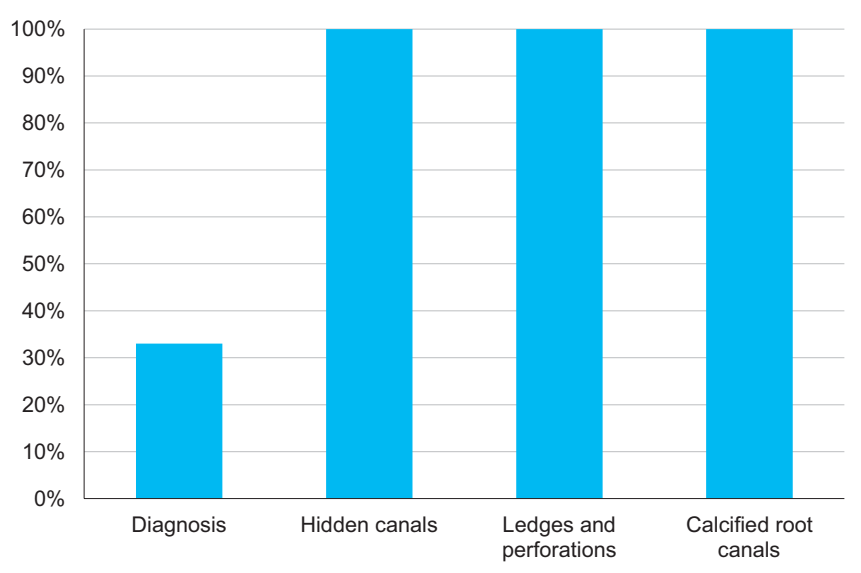

FIGURE 1. The usage of DOM during endodontic therapy 


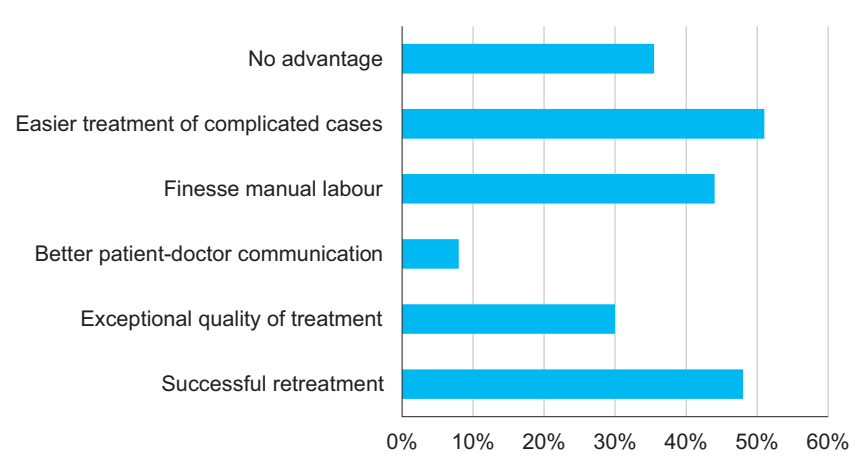

FIGURE 2. Advantages of dental microscope usage

the asked doctors said they would prefer to send patients to an endodontist. The results also showed that $86 \%$ of specialized practitioners do not have information about the dental operating microscope, but almost $50 \%$ would invest in buying one in the future.

In total, $83 \%$ of the asked endodontists stated that they use the microscope when they face complicated cases during root canal treatment, while $17 \%$ do not use it because the private practice does not own one or are not interested in using it. Almost $50 \%$ of the doctors use magnification in odontotherapeutic interventions also. When asked about where they had gained information on the use of the dental microscope, $57 \%$ answered during post-university courses, $28 \%$ at the university, while $15 \%$ did not have any information about it. Except for three persons, all doctors would invest in an operating microscope in the near future.

The dental microscope is used during endodontic interventions to establish a correct diagnosis in a smaller percentage, but it is used every time when complicated cases appear, such as hidden canals, ledges or perforations, when calcified root canals need to be penetrated, or when fractured instruments need to be removed (Figure 1).

Figure 2 and Figure 3 present the opinion of dentists about the advantages and disadvantages of dental operating microscope usage.

TABLE 1. Statistical analysis of microscope usage in the three groups

\begin{tabular}{lccc}
\hline & YES & NO & Row Totals \\
\hline Group 1 & 15 & 3 & 18 \\
Group 2 & 3 & 18 & 21 \\
Group 3 & 1 & 29 & 30 \\
Column Totals & 19 & 50 & 69 (Grand Total) \\
\hline
\end{tabular}

The $p$ value is $<0.00001$. The result is significant at $p<0.005$.

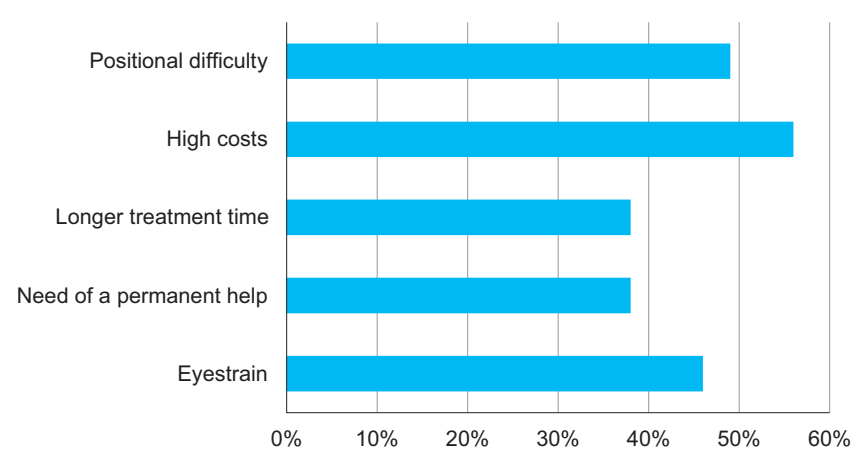

FIGURE 3. Disadvantages of dental microscope usage

We found statistically significant differences between the three groups regarding their attitude towards using the dental operating microscope (Table 1).

\section{DISCUSSIONS}

The introduction of the dental operating microscope represents a big step forward in dentistry, especially in the field of endodontics. Until the possibility of magnification, root canal therapy was performed in "total blindness", complications appeared more frequently, and retreatment success was considerably lower. ${ }^{1}$

The dental operating microscope is used mainly during root canal therapy by the specialized (endodontist) practitioners. Working under magnification is preferred in complicated cases or retreatment, but it is not used habitually. ${ }^{8}$

DOM usage assures a higher quality of treatment and eases root canal therapy when complicated cases need to be resolved. ${ }^{9}$ High costs, eyestrain, and positional difficulty are considered the disadvantages of working under magnification. Similar results were found in Kersten's study and other studies about the use of microscope in endodontics. ${ }^{10,11}$

The use of dental microscopes is getting more popular among practitioners of other specialties during dental interventions other than root canal therapy, such as coronal restoration, prosthetics, or periodontal surgery.

Although the dental operating microscope is used in a small percentage of dentists in Tîrgu Mureș and mainly by endodontists, young doctors of other specialties seem to be interested in gaining information about working under magnification and even about buying a microscope for their private practice.

One limitation of this study could be that we restricted the questionnaire only to dental operating microscope usage, which has the highest costs and has the most difficult handling compared to other optical aids. 


\section{CONCLUSIONS}

Endodontists use magnification mainly during root canal treatment. Working under magnification is awakening the interest of doctors of other specialties also, especially during conservative treatments or surgical interventions. More private practices should invest in acquiring a microscope, and young general practitioners should be motivated in using it during dental treatments.

\section{CONFLICT OF INTEREST}

Nothing to declare.

\section{REFERENCES}

1. The Use of the Operating Microscope in Endodontics. Available at: http:// perfendo.org/docs/Endodonzia.pdf

2. Apotheker H, Jako GJ. A microscope for use in dentistry. J Microsurg. 1981;3:7-10.
3. Arens DE. Introduction to magnification in endodontics. J Esthet Restor Dent. 2003:15:426-439.

4. Carr G, Murgel CA. The use of the operating microscope in endodontics Dent Clin North Am. 2010; 54:191-214.

5. Jaeken B, Tabernero J, Schaeffel F, Artal P. Comparison of two scanning instruments to measure peripheral refraction in the human eye. J Opt Soc Am A Opt Image Sci Vis. 2012;29:258-264.

6. AAE Special Committee to Develop a Microscope Position Paper. AAE Position Statement. Use of microscopes and other magnification techniques. J Endod. 2012;38:1153-1155.

7. Mamoun JS. A rationale for the use of high-powered magnification or microscopes in general dentistry. Gen Dent. 2009;57:18-26.

8. Mines P, Loushine RJ, West LA, Liewehr FR, Zadinsky JR. Use of the microscope in endodontics: a report based on a questionnaire. J Endod. 1999;25:755-758.

9. dos Santos Accioly Lins C, Verçosa de Melo Silva EM, Agnelo de Lima G, Acioly Conrado de Menezes SE, Coelho Travassos RM. Operating microscope in endodontics: A systematic review. Open Journal of Stomatology. 2013;3:1-5

10. Kersten DD, Mines P, Sweet M. Use of the microscope in endodontics: results of a questionnaire. J Endod. 2008;34:804-807.

11. Alrejaie M, Ibrahim NM, Malur MH, AlFouzan K. The use of dental operating microscopes by endodontists in the Middle East: A report based on a questionnaire. Saudi Endodontic Journal. 2015;5:134-137. 